\title{
A Discussion on the Amusement and Market of Basketball Games 籃球運動的娛樂性與籃球市場
}

\author{
Xiaoying TAN Chun XIA
}

Shanghai Institute of Physical Education, Shanghai, CHINA

譚曉悢夏春

中國上海體育學院

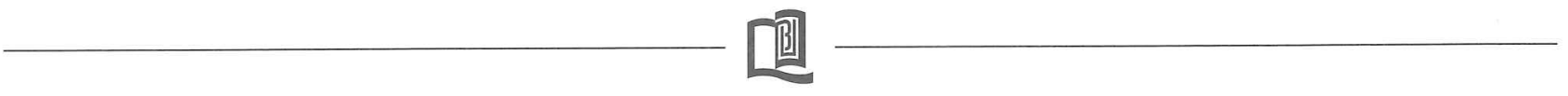

\begin{abstract}
The market of the Chinese Basketball Association (CBA) is not so ideal, though it has come into existence for eight years. We should study the NBA from the United States that exerts amusement of basketball sport well, and then this come hold tight the market with draw on the fan.
\end{abstract}

Key word: League of the CBA, Development of the NBA, Market of basketball sport, Amusement of basketball sport.

\section{摘 要}

我國的 CBA 籃球職業聯賽成立 8 年來, 市場不盡如人意。我們應向美國的 NBA學習, 一切從市場的需求出發, 充分發揮籃球運 動的娛樂性，以此來抓住市場和吸引球迷。

\section{美國疃業籃球運動的發展及現狀}

籃球運動自 1891 年創建以來，以其獨特的魅力很快成為 奥運會正式比賽項目之一, 在世界各地擁有廣泛的群眾基礎。 在籃球運動的發源地, 被譽為“籃球王國”的美國, 籃球是最 受歡迎的運動之一。NBA的比賽更是吸引了世界各地的球迷， 每年有超過 150 個國家和地區的電視台直播 NBA 的總決賽。 NBA 也因此成為全球最成功的體育組織之一。NBA 的成功並 非一帆風順, NBA 成立於 1946 年, 原名 ABA (American Basietball Association）, 於 1949 年與另一籃球組織 NBL 合併 後三式更名 NBA，從1949 年至 1966 年这近 20 年, NBA 發展 相當緩慢。6 0 年代後期 NBA 出現了張伯倫和拉塞爾兩位超級 巨星, 籃球比賽的攻防節奏加快、對抗加強, 並出現了精彩的 大力扣籃, 競爭也趨於激烈。由於比賽的觀賞性和精彩程度的 提高, 漸漸的吸引了球迷的注意。但因經營不善, 以及與電視 轉播商談判的失敗, $\mathrm{NBA}$ 在困境中掙扎。至 70 年代後期 $\mathrm{NBA}$ 與另一個職業籃球聯盟 ABA（American Basketball Association） 合併, 球隊增加到22個, 形成了一個完整、規範的籃球市場。 從此, NBA對美國職業籃球從人才、資金到市場行銷的全部壟
斷。70年代末 NCAA（全美大學生體育聯盟）紅極一封的兩 位球星 “魔術師” 詹森和 “大鳥” 伯得進入 $\mathrm{NBA}$, 加之 NBA 成功的市場運營和推廣, 以及著名電視轉播商的介入, NBA進 入了黄金時代。9 90 年代天皇巨星 “飛人” 喬丹更是將 NBA 推 向另一個高潮。進入新世紀後, 一大批新生代好手, 奥尼爾、 科比、艾佛森、溫斯.卡特等在 NBA 又刮起了新一輪的風暴。

NBA 的成功在很大程度上歸功於其充分發掘籃球運動的 娛樂性。通過對球星個人的人格魅力, 極富觀賞性的技術動 作; 各支球隊擁有自身的獨特戰術風格和特點; 以及比賽中快 速轉換的攻防節奏、激烈的對抗等措施的强調來增加NBA球賽 的觀賞性。並通過每年一度的全明星賽、扣籃大賽、三分遠投 大賽、及觀眾參與的百萬美圓投籃等形式多樣的娛樂推廣活 動, 來吸引更多的公眾及媒體的關注。

綜觀整個 NBA 發展史，NBA 似乎成了一個大型 “造星” 工廠。每個年代的代表人物以其獨特、鮮明的個性及其精湛的 球技吸引了大量的球迷, 正是廣大球迷構成了 $\mathrm{NBA}$ 市場的基 石。同時, 這些球星也吸引了廣告商的青睞。世界著名運動品 
牌競相爭取 NBA 球星作為其產品代言人。NBA 90 年代的“天 皇巨星” 喬丹, 在其鼎盛時期曾為美國帶來了數十億美圓的經 濟效益。1994年喬丹首次宣佈退役, 使得美國股市為之大跌。

NBA 現有的 29 支球隊, 各有特色。根據每個隊伍所處的 地理位置、城市特點、及球隊歷史, 他們各自取了富有地方風 格的隊名。各隊擁有自己的球星, 以及圍繞核心隊員的技術特 點所制定的獨有的戰術風格。因此, 每支球隊輕易地贏得了本 地球迷的認同感。

為提高比賽的觀賞性和精彩程度, NBA 制定了不同於國 際籃聯的比賽規則。為提高比賽的攻防速度, NBA 率先啟用 24 秒的進攻時間限制, 並取消區域聯防 $(\mathrm{NBA}$ 為使本國球員適 應國際籃聯的比賽, 於 2001-2002 賽季開始, 允許使用區域聯 防, 但制定了防守 3 秒的規則的限制悝Y在進行聯防時, 限制 區內無進攻隊員的情況下, 防守隊員不可在限制區內停留超過 3 秒。) 0 為增加比賽的激烈程度和眯念, NBA 率先採用四節 制, 每節比賽時間為12分鐘, 並增加了暫停次數, 即每個半場 時間 可以有一個 20 秒的短暫停, 並允許場上控球隊員要暫 停。這些規則使得NBA的比賽常常是瞬息萬變, 往往到比賽的 最後 1、2 秒鐘才分出勝負, 這也正是吸引球迷的關鍵所在。

NBA每年一度的全明星賽, 更是被稱作 “球迷的節日”。 每年由各支球隊所在的城市輪流舉辦, 在為期一周的時間, 球 迷們不僅可以欣賞到球星們的精彩表演, 還可以自己參與各種 比賽, 並有機會和自己所喜愛的球星同場競技, 並贏取百萬大 獎。

所有的這些舉措不僅使得 NBA 成為當代美國最受歡迎的 運動之一, NBA還作為一種獨特的文化現象, 深得美國公眾的 認可。

從1987 年的麥當勞錦標賽開始, NBA跨出全球化腳步。 在1992年西班牙巴賽隆納奧運會上，以喬丹、巴克利、尤因等 一個個耳熟能詳、個性鮮明的 NBA 全明星組成的美國“夢之 隊”，憑藉其精湛的技藝，充滿激情的表演。不僅席捲奧運賽 場, 同時征服了全世界球迷, 為NBA的國際化打下了堅實的基 礎。為了使NBA更加具有國際影響, 在短短的十幾年的時間, $\mathrm{NBA}$ 的決策者們通過吸收加拿大的球隊加入 NBA，在美國本 土以外舉行NBA比賽, 派球星出國表演, 向外國贈送比賽轉播 權, 開發NBA的產品等手段進一步擴大自己的世界影響。但這 些推廣手段還有一個致命的缺點, 那就是不能使外國球迷產生 真正的認同感。為此, NBA 開始逐漸吸收外籍球員進入 NBA 打球。至2001-2002賽季末, 共有51位分別來自30個國家的國 際球員在 NBA 效力。NBA 正在成為一個國際性組織, 受到越 來越多國家球迷的關注和喜愛。

\section{中國籃球婵動(GBA)的發展及現狀}

我國現有王治郅、巴特爾兩大中鋒效力於 NBA，“小巨 人”姚明本賽季也將以去年的狀元秀身份加盟NBA。由於三大 中鋒的加入, 中國球迷關注NBA的熱情空前高浱。今年三月, 當已披上NBA掘金隊戰袍的巴特爾和中國國家隊的隊友、效力 于小牛隊的王治郅首次在 $\mathrm{NBA}$ 賽場上相遇時, 有 2 億多球迷在 電視機前觀看了這場比賽, 由此可見我國籃球市場潛力巨大。

我國男子籃球甲 $\mathrm{A}$ 聯賽（簡稱 $\mathrm{CBA}$ ），自 1995 年起成為 職業聯賽, 經過七年的發展, 成為國內發展最快、最受歡迎及 水平最高的男籃職業聯賽, 亚鋭意發展成為世界三大籃球聯賽 之一及亞洲第一聯賽。 $\mathrm{CBA}$ 聯賽擔負著提高我國籃球運動的 競技水平, 使我國的籃球運動水平達到世界一流强隊水平的重 任。 $\mathrm{CBA}$ 聯賽在人才的培養上創出了較好的成績, 培養了進軍 NBA的三大中鋒。然而職業化的另一重要因素市場效應, 卻因 此被忽視, $\mathrm{CBA}$ 的市場不盡如人意。

踓然, 隨著比賽制度、推廣方式的改進, $\mathrm{CBA}$ 的上座率 和收視率都有所提高, 特別是 2001-2002 賽季的 CBA 總決賽, 觀眾上座率澾到 100\%, 門票成為熱銷品。但是, 從總體上 看, 我國觀看 $\mathrm{CBA}$ 的觀眾人數遠少於觀看 NBA 的人數。據統 計我國約有 2 億籃球迷, 據 TOM 體育調查顯示, 籃球迷的教 育水平多為高中或以上, 觀眾以年青男性為主。因此, 本文通 過對北京、上海兩地高校的 200 名籃球迷從喜歡籃球運動的誘 因、對 NBA 及 CBA 的瞭解程度、觀看籃球比賽的量、以及對 CBA發展的建議等方面進行調查, 訪問。調查結果顯示, 球迷 們對 NBA 的膫解程度遠遠高於對 CBA的瞭解。 $80 \%$ 的球迷熟 悉所有 NBA 球隊的隊名、及各隊主要球星的名字, 而有 $50 \%$ 的球迷不知道CBA共有幾支球隊。在2001-2002的 NBA 賽季, $90 \%$ 的球迷每週至少觀看一場電視直播或轉播的 NBA 賽事, 超過 98\% 的球迷觀看了所有場次的 NBA 總決賽。但僅有不到 $15 \%$ 的球迷每週至少觀看一場 CBA 的電視直播或轉播。究其 原因, 主要有以下幾點。

\section{影響 CBA 市場的因素及解決對策}

首先, 儘管所有的球迷都有個共同的願望我國的籃球水平 早日達到世界一流, $\mathrm{CBA}$ 能成為世界一流的聯賽。但由於 $95 \%$ 以上的球迷是因為觀看 NBA的比賽或在 NBA球星的影響 下, 喜歡籃球運動的, 這在很大程度上造成了球迷們對NBA的 心理傾向。其次, 球迷們對 $\mathrm{CBA}$ 聯賽總體的評價是缺乏觀賞 性, 主要表現在打法陳舊、單調, 攻防節奏緩慢, 缺乏懸念, 以及球星沒有足夠的號召力。再就是, 球迷們普遍認為媒體對 $\mathrm{CBA}$ 的關注程度不夠。 
儘管, 愛好 “霸權” 的美國人長期以來霸佔著籃球市場, NBA 也正在大力拓展海外市場, 尤其看好我國的巨大市場潛 力。但我們應該同時看到, 正是由於越來越多希望瞭解 $\mathrm{NBA}$ 和 喜歡 $\mathrm{NBA}$ 的人, 造成我們的籃球迷隊伍的不斷擴大。因此, 我 确應以此作為市場的依託, 一切從我國籃球市場的需求出發, 充分發揮籃球運動的娛樂性, 並結合有效的媒體宣傳。不僅要 抓住 2 億球迷的市場, 還應該挖掘更大的潛在市場。在調查中 顯示，有超過 95\% 的球迷觀看了 2000-2001、2001-2002 賽季 的 CBA 總決賽。吸引如此多球迷關注的原因很簡單, 20002001 賽季總決賽的看點是姚明的崛起和打破 “八一” 不敗的神 話, 2001-2002 賽季總決賽的看點是聯賽冠軍的易主, 加上上 海東方和八一火箭, 兩支具有鮮明戰術風格的隊伍, 在高速的 攻防轉換、以及交錯上升的比分中進行的比賽。由此可見, $\mathrm{CBA}$ 聯賽要抓住市場、吸引球迷, 就一定要膫解市場的需求, 增加比賽的精彩程度和懸念, 加大對球星的培養力度, 利用媒 體的宣傳加強賽事的推廣工作。

\section{參考書目}

1. 宗衛鋒, 蘇文山, 段笑林。。我國籃球職業化的必要性 和影響因素初步分析．體育高呚研究，1996(1)，47-50.

2. 趙國華。對建設具有中國特色的職業籃球的影響因素 和模式體系的研究. 北京體育師範學院 1996 碩土研究生 學位論文。

3. 曾志雄。 影響我國實行職業化籃球俱樂部的若干障礙 因素分析及對策, 廣州體育學院 1996 年碩士研究生學位 論文。

4. 歐陽金樹。企業贊助與新人類的休閒活動街頭鬥牛為 例。台灣體育。1998-10-12.

5. 趙映輝, 王安平。淺析職業籃球的商業價值及我國籃 球市場的開發，西安體育學院學報．1999；16(2)；2022 。

6. 梁建平, 李敦來, 湯悟先。對我國籃球職業化改革的 思考。北京體育大學學報１999；22（2）；24-27。

\section{蓪 訊}

\author{
作者：譚曉縜 碩士 講師 \\ 中國上海體育學院體育敉育系
}

地址：上海市 臨平路 333 號瑞虹新城 9 座 1304, 200086 電郵：xiaoying1309@yahoo.com.cn 